\title{
Conception of Information Construction for Numerical Control Training Base
}

\author{
Dongfang $\mathrm{Hu}^{1, \mathrm{a}^{*}}$ and Jianwei Guo ${ }^{1, \mathrm{~b}}$ \\ ${ }^{1}$ School of Mechatronics Engineering, Henan University of Science and Technology, Luoyang, \\ 471003, China \\ ahdf@haust.edu.cn, ’guojianwei1991@yeah.net
}

\begin{abstract}
Keywords: Numerical control training; Training base; Construction; DNC Technology; Network communication
\end{abstract}

\begin{abstract}
Based on the analysis of the DNC technology, with reference to the modern enterprise workshop production operation mode, and research from the domestic some college training base construction experience. Summarizes related network communication key technology. Elaborated under the network environment. According to the current condition of numerical control training base construction practice of design. According to the teaching practice and training base construction experience, the function of each module of DNC is described in detail, and the overall planning of the hardware and software of the training area is carried out. The feasibility of the network construction of the advanced manufacturing training area is verified based on the existing training conditions and reference design of modern enterprise workshop production operation mode, which has great significance to the long-term development of the training base in Colleges and Universities.
\end{abstract}

\section{Introduction}

The informationization of the manufacturing industry has matured in today's ubiquitous network society. As a senior blue collar training should be urged the education informationization to avoid the students after graduation to the training in higher vocational colleges. The school and factory seamless docking, is to cultivate a large number of operators who can keep up with the pace of development of manufacturing industry, especially the occupation colleges must bear the glorious task, and the first mission is complete the construction of training base to improve modernization [1]. Information construction for $\mathrm{NC}$ training base as the representative of advanced manufacturing industry should be like this.

Networked Manufacturing. Networked manufacturing is a generic terms of manufacturing enterprise based on the network of various manufacturing activities and involved in the manufacturing technology and the floorboard of the manufacturing system. Among them, Network including Internet and Ethernet; Manufacturing companies include individual enterprises, enterprise groups, and for a market opportunity and temporary form of all kinds of manufacturing enterprises and companies such as virtual enterprise alliance; Manufacturing activities including marketing, product design and development, the material resources organization, production process, product transportation and sale and after-sale service and other enterprises involved in all related activities and work. At present, the most majority of manufacturing companies of numerical control equipment to conducting network integration management [2], network manufacturing technology [3] is getting more and more widely used, it is the link to realize the CAD/CAM and computer aided production management system integration, it is also a form of mechanical process automation. It takes computer technology, communication technology, numerical control technology, as the basis, putting numerical control machine and the upper control computer into integration, so as to realize the centralized control and management of NC machine tool and numerical control machine tool and the exchange of information between the upper control computer.

Numerical Control System Meshing. A significant characteristics of open NC system [4] is the numerical control system meshing. In the modern sense of network numerical control system taking 
communication and resource sharing as methods, and workshop even enterprise inside the organic integration of manufacturing equipment as the goal, to support ISO - the OSI network interconnection standards, it can support Internet/Ethernet standards, and also has a strong openness, its networking through standard network equipment to implement, without the need for other interface components or PC.

DNC Technology. DNC research began in the $1960 \mathrm{~s}$, its beginning meaning is Direct Numerical Control (Direct digital Control), refers to the number of sets of CNC equipment directly connected on a central computer, central computer is responsible for the management of the NC program and transmission. Since the $1990 \mathrm{~s}$, with the rapid development of various new technologies, DNC technology is in rapid development, the concept of DNC [5] is in a qualitative changing, now the DNC is a short form of Distributed Numerical Control, its literal translation is the Distributed digital Control, the international standard ISO2806 in 1994 to DNC is defined as: the distribution system between production management computer and multiple CNC system data classification system. Now the broadest sense of DNC is moving toward to taking numerical control equipment integration as core in the direction workshop level integrated development [6], with mature computer technology, communication technology, numerical control technology as the foundation, put NC machine tools and the upper control computer integrated through the network transmission, program management, edit the simulation, the function such as machine tool monitoring and data collection, putting different objects in different locations such as the machine tool, server, engineers, workers, managers in the same DNC system for unified management, so long as to realize the centralized control management of NC machine tools, as well as realized the information exchange between the numerical control machine tool and the upper control computer. Parts processing program or machine program stored in shared memory, the computer in accordance with the contract and request, distribute programs and data to the machine tool, it could display or edit data which is relevant with control process. In addition, the system computer also has a function to schedule production system, automatic programming, automatic program check and correction, and system maintenance etc. And it is a small but quick effect investment.

DNC Module and Function. The domestic and abroad DNC has plenty of categories, its function is different from another, the following taking the famous CIMCO DNC system as an example, making a brief description for DNC and its main function modules. CIMCO DNC is a leading product in Danish CIMCO software company, the company was founded in 1991, it is the leader of DNC solution in the world, its products are widely applied to Boeing, lockheed Martin, mercedes-benz, BMW, etc. In the global users, the total installed capacity is more than 40 ten thousand machine tools. It is the most amounts installed DNC system in the world.

CIMCO DNC system software [7] part is consists of DNC - Max network communication, NC Base NC program management, CIMCO EDIT CNC program editing and simulation, the MDC - Max machine tool monitoring and data collection [8], the four parts is an organic whole, these part constitute CIMCO DNC system. The function of the four parts as follows:

(1) DNC-Max network communication

The DNC has outstanding stability and reliability, favorable system compatibility, powerful network communication function, convenient to upload, download, efficient remote comparison functions, perfect online processing function, unique forced upload function, transparent transmission, abundant transmission management functions.

(2) NC Base NC program management

NC program management have advanced system architecture, efficient NC management, powerful permissions management, flexible process management, version management, humanization of task management, comprehensive paperless manufacturing, easy to operate the touch screen large ICONS, convenient application, reliable backup and recovery, and good integration.

(3) CIMCO EDIT NC program edit and simulation

CIMCO EDIT have convenient program editing, F/S dynamic adjustment of practical data operation, fixed loop function of macro definition, program is more intelligent, powerful 3-5 axis simulation, the 
results of simulation output function, cutting time statistics program, program processing range of statistics.

(4) MDC-Max Machine tool monitoring and data collection

MDC-Max have remote monitoring machine condition, real-time analysis and processing information, accurate analysis of machine tool failure, rapid positioning production bottlenecks, provide basic data for MES.

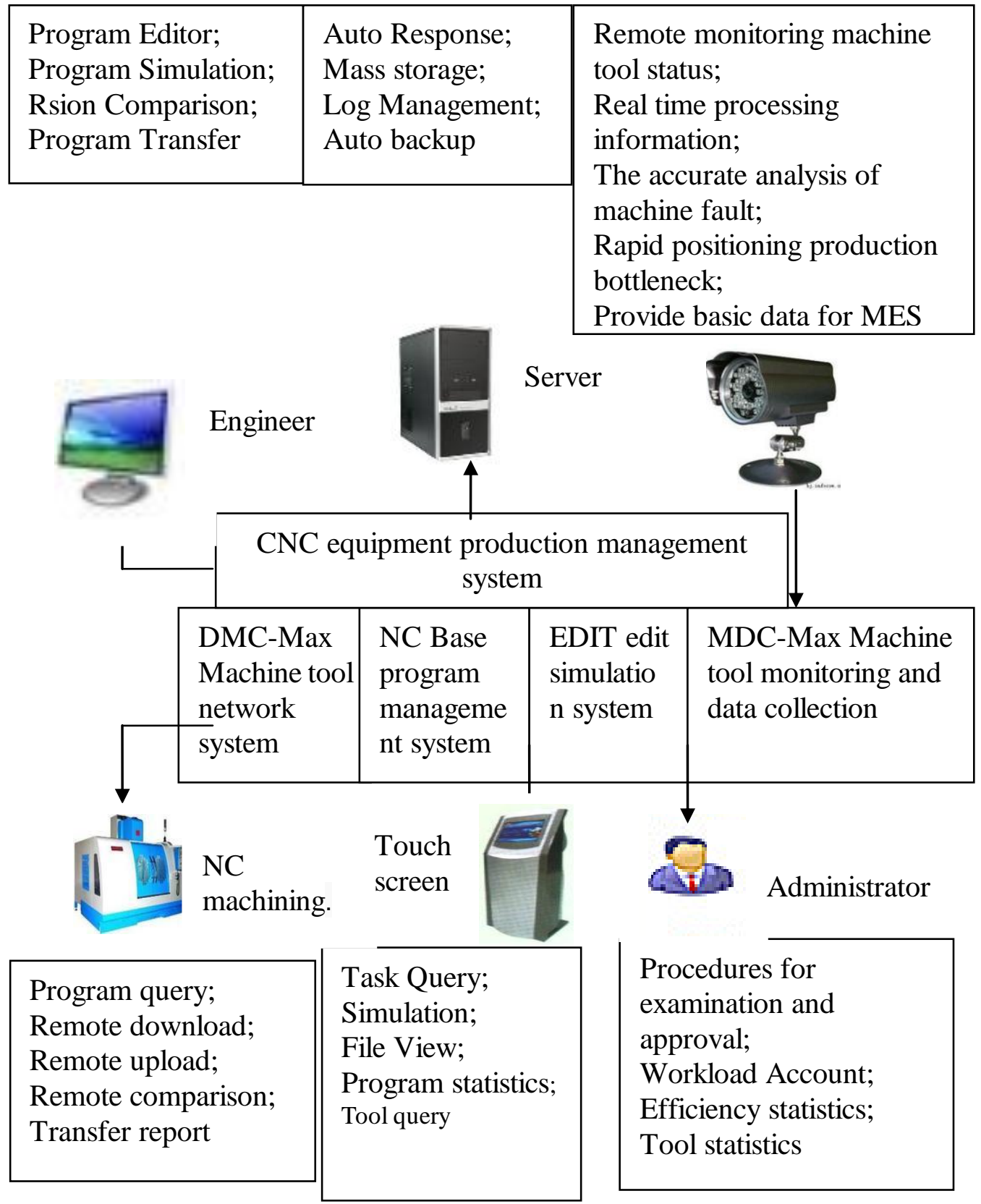

Figure 1. Functional block diagram of each part of DNC

\section{Network Construction of the Practice Base}

The Network Aim of the Advanced Manufacturing Practice Area. Through the understanding of networked manufacturing and DNC technology, we can also plan advanced manufacturing practice area network construction plan:

(1) To realize NC training network environment [9]. Guarantee NC training area data communication with $\mathrm{CAD} / \mathrm{CAM}$ training room open, ensure the training area between stability, safety 
and reliability of data transmission, make NC training area network running and processing and manufacturing automation. Provide good training for networked numerical control technology training project conditions. Structures, numerical control machine tools, CAD/CAM software and simulation software NC machining information integration platform for the teaching, improving practice teaching conditions to let the student feel the running mode of modern manufacturing, experience to the mechanical equipment manufacturing case design, drawing, $\mathrm{CNC}$ programming and machining molding the whole process, strengthen the practice teaching effect. In addition to undertake mechanical experiment training with the school, they also can undertake various manufacturing companies staff skill training, and improve the quality of the employees' skills.

(2) Improve the practice teaching effect [10]. Through network building, students in the practice teaching, should make full use of CAD/CAM software for parts design, simulation and analysis of processing technology, and strengthen the proper use of numerical control software using the computer and the NC machining program codes. After the Simulated processing program, the training teacher should confirm deposit directly to NC machining program and put it to the server. When NC practice operation to program reads directly to numerical control lathe, implement on-line automatic processing. At the same time, students can also control system platform through the machine tool, to realize the detecting state of NC machine tools, machine tool control data and actual operation network monitoring.

Practice Area of Hardware and Software Configuration. According to the reality, advanced manufacturing practice area can plan three training venues, including ordinary mechanical processing practice area, $\mathrm{NC}$ machining training area, $\mathrm{CAD} \backslash \mathrm{CAM}$ training rooms. The $\mathrm{NC}$ machining technology training area is equipped with advanced $\mathrm{CNC}$ machine tool equipment, at least 1 two processing center, CNC milling machine, $4 \mathrm{CNC}$ lathe, machining center equipped with mainstream FANUC system; FANUC CNC milling configuration and SIMENSE system a set; Numerical control car is equipped with a FANUC, a SIMENSE, two huazhong century star system. Main consideration is to make students master both now the mainstream of the numerical control system, and be familiar with domestic system, along with the development of the domestic numerical control technology, the ubiquity of the domestic system is only a matter of time, we cannot and will not allow the old ass behind with others.

CAD/CAM training rooms equipped with a series of software , such as Autocad, Mastercam, UG, Pro/E, Solid works, CAXA, as well as Ansys, the finite element analysis software, and walter CNC simulation software and series of CAD/CAM software, which is available for computer aided design, $\mathrm{CAD} / \mathrm{CAM}$ training, $\mathrm{NC}$ machining simulation design, $\mathrm{UG}$, course training tasks of mechanical and electrical engineering department, it can also complete the numerical control programming and virtual machining and other design and floor plan production, the design of space diagram and so on.

At present, the modern manufacturing industry CAD/CAM software combined with networking NC equipment is the trend of development. Establishing local area network in the CAD/CAM training room, connecting with the campus network, then connected with $\mathrm{NC}$ machine tools equipment in training area. The NC machining area can achieved that NC could transfer program from computer equipment to each machine, no longer rely on the artificial intelligent, and the NC machining program is a stable, safe and reliable management. At the same time, it could query the running state of the equipment and equipment through the network training area at any time, and remote monitoring of machining training process, after network in training area, the teaching training project by independent training project simulation module to the production process of comprehensive training transformation. The mechanical parts drawing, machining process, NC machining simulation, $\mathrm{NC}$ program compiling and training project, which was conducted in the CAD / CAM laboratory design room, after the preparation of the $\mathrm{NC}$ program by training teachers after confirmation procedures in accordance with the classification of storage, stored in the DNC server machine category. CNC machine tools can only read NC program in the processing of the work piece, the program cannot be modified. Practice teaching data control flow chart as shown in Fig. 2: 


\section{Machine tool control system platform}

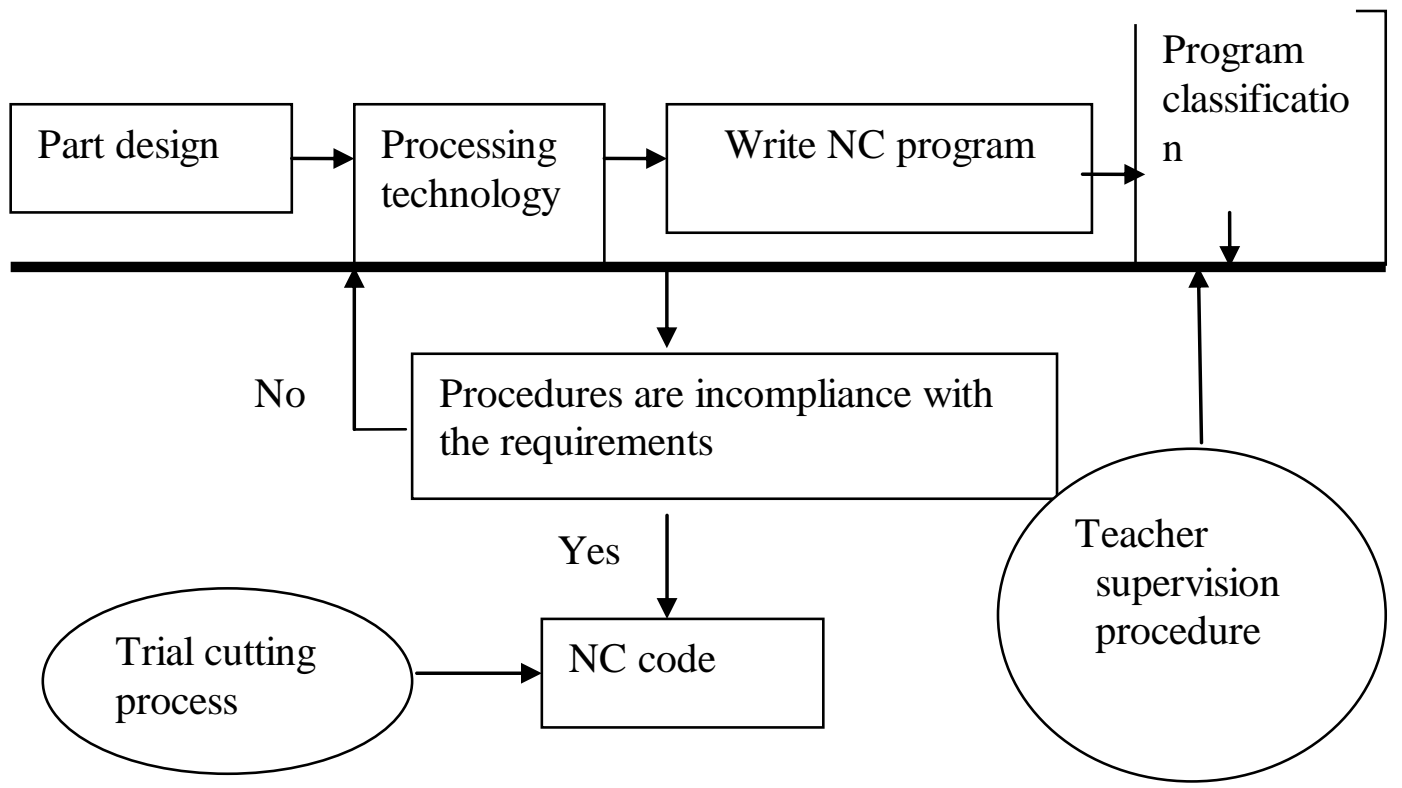

Figure 2. Two platform of machine tool control system

\section{Conclusion}

Through analysed the DNC technology, reference the production operational mode of modern workshop, absorbed training base construction experience of some domestic college and summarized related network communication key technologies, the improvement project was designed according to the training condition and the aim of aforementioned advanced manufacturing practice network construction was achieved.

\section{Acknowledgement}

The authors gratefully acknowledge the National Superior Course and Bilingual Teaching Demonstration Course for financial support of this research work and the Project for Education and Teaching Reform of Henan University of Science and Technology (No. 2012N-007).

\section{References}

[1] J.J. Wang, F.Q. Jang: Study on Building of NC Training Base, (2005) No.10, p.85 (In Chinese).

[2] S. Liu: More Safe and More Reliable Integrated Linking System for CNC Machine Tools, (2005) No.07, p.81 (In Chinese).

[3] J.R. Huang, B. Wu: The Research and Application of Networked-manufacturing Technology Based on DN. (2006) No.10, p.40 (In Chinese).

[4] H. Shi, Q.G. Cai: Status Quo and Development Trend of Open CNC System, 43 (2005) No.06, p.18 (In Chinese).

[5] R. Rui, J. Bai: Actualization and Integration of DNC System, (2009) No.05, p.127 (In Chinese).

[6] Z.M. Chen, Research on DNC Networking Management System for Digital Workshop (MS., Hunan Normal University, China 2011), p.23 (In Chinese).

[7] X. Zhang, L.D. Zhou and M. Lei: Application of DNC System in Engineering Training, (2006) No.05, p.91 (In Chinese). 
[8] D.W., Feng: Application of CIMCO DNC-Max machine tool networking system, (2006) No.11, p.122 (In Chinese).

[9] Y. Wang: Study on NC training base construction of the network environment, 22 (2012) No.2, p.52 (In Chinese).

[10] H.W. Ma: Discussion on the Educational Model under Network Environment, 30(2011) No.33, p.277 (In Chinese). 